\title{
The Interaction of Galling and Oxidation in 316L Stainless Steel
}

DOI:

10.1016/j.wear.2020.203234

\section{Document Version}

Accepted author manuscript

Link to publication record in Manchester Research Explorer

\section{Citation for published version (APA):}

Rogers, S. R., Bowden, D., Unnikrishnan, R., Scenini, F., Preuss, M., Stewart, D., Dini, D., \& Dye, D. (2020). The Interaction of Galling and Oxidation in 316L Stainless Steel. Wear, 450-451.

https://doi.org/10.1016/j.wear.2020.203234

\section{Published in:}

Wear

\section{Citing this paper}

Please note that where the full-text provided on Manchester Research Explorer is the Author Accepted Manuscript or Proof version this may differ from the final Published version. If citing, it is advised that you check and use the publisher's definitive version.

\section{General rights}

Copyright and moral rights for the publications made accessible in the Research Explorer are retained by the authors and/or other copyright owners and it is a condition of accessing publications that users recognise and abide by the legal requirements associated with these rights.

\section{Takedown policy}

If you believe that this document breaches copyright please refer to the University of Manchester's Takedown Procedures [http://man.ac.uk/04Y6Bo] or contact uml.scholarlycommunications@manchester.ac.uk providing relevant details, so we can investigate your claim.

\section{OPEN ACCESS}




\title{
The Interaction of Galling and Oxidation in 316L Stainless Steel
}

\author{
Samuel R. Rogers ${ }^{\mathrm{a}, *}$, David Bowden ${ }^{\mathrm{b}, \mathrm{c}}$, Rahul Unnikrishnan ${ }^{\mathrm{b}}$, Fabio Scenini ${ }^{\mathrm{b}}$, Michael Preuss ${ }^{\mathrm{b}}$, David \\ Stewart $^{\mathrm{d}}$, Daniele Dini $^{\mathrm{a}}$, David Dye ${ }^{\mathrm{a}}$ \\ ${ }^{a}$ Imperial College, South Kensington, London $S W 72 A Z, U K$ \\ ${ }^{b}$ Department of Materials, The University of Manchester, Sackville Street Building, Manchester M1 3BB, UK \\ ${ }^{c}$ UK Atomic Energy Authority, Culham Science Centre, Abingdon OX14 3DB, UK \\ ${ }^{d}$ Rolls-Royce plc, Raynesway, Derby DE21 7WA, UK
}

\begin{abstract}
The galling behaviour of 316L stainless steel was investigated in both the non-oxidised and oxidised states, after exposure in simulated pressurised water reactor (PWR) water for $850 \mathrm{~h}$. Galling testing was performed according to ASTM G196 in ambient conditions. 316L was found to gall by the wedge growth and flow mechanism in both conditions. This resulted in folds ahead of the prow and adhesive junction, forming a heavily sheared multilayered prow. The galling trough was seen to have failed through successive shear failure during wedge flow. Immediately beneath the surface a highly sheared nanocrystalline layer was seen, termed the tribologically affected zone (TAZ). It was observed that strain-induced martensite formed within the TAZ. Galling damage was quantified using $\mathrm{R}_{t}$ (maximum height - maximum depth) and galling area (the proportion of the sample which is considered galled), and it was shown that both damage measures decreased significantly on the oxidised samples. At an applied normal stress of $4.2 \mathrm{MPa}$ the galled area was $14 \%$ vs. $1.2 \%$ and the $\mathrm{R}_{t}$ was $780 \mu \mathrm{m} v$ s. $26 \mu \mathrm{m}$ for the non-oxidised and oxidised sample respectively. This trend was present at higher applied normal stresses, although less prominent. This difference in galling behaviour is likely to be a result of a reduction in adhesion in the case of the oxidised surface.
\end{abstract}

\section{Introduction}

Cobalt-based hardfacing alloys are used in nuclear applications on account of their high wear and galling resistance. Under the ALARA (as low as rea5 sonably achievable) principle [1], cobalt must be removed from nuclear applications. Cobalt is not used ${ }^{25}$ in the reactor pressure vessel (RPV) and so components do not undergo direct irradiation. However, after extended use, components wear, with wear debris travelling into the RPV, becoming irradiated and transmutating from ${ }^{59} \mathrm{Co}$ to ${ }^{60} \mathrm{Co}$, which is a gamma ${ }^{30}$ radiation source. Since the wear debris will continue to travel around the primary circuit, it may cause additional doses to personnel working on and around 15 the primary circuit, including during shutdowns. As such, alternative Co-free materials are desired for tri- ${ }^{35}$ bologically sensitive components such as valve seats.

Austenitic stainless steels containing hard particles have been suggested for some time as replacement

\footnotetext{
${ }^{*}$ Corresponding author

Email address: srr13@ic.ac.uk (Samuel R. Rogers)
}

20 materials for the Stellite ${ }^{\mathrm{TM}}$ family of alloys (Co-Cr$\mathrm{W}$ with $\mathrm{W}$ - and Cr-carbides), which are currently the most widely used cobalt alloys used in nuclear applications. In both cases, the alloy matrix is fcc austenite, with the ability to form strain-induced martensite (hcp $\epsilon$-martensite in Stellite ${ }^{\mathrm{TM}}$ and bct $\alpha^{\prime}$-martensite in austenitic stainless steels). A number of galling resistant stainless steel alloys have been developed over the past four decades which incorporate martensite formation during wear [2-7]. However, none have been considered suitable for wide-scale use in reactors, owing to their reduced galling resistance at elevated temperature, such as those seen in light water reactors. Further work is therefore necessary to develop a stainless steel which is galling resistant at elevated temperatures.

The ASTM G40-15 definition of galling is as follows [8]:

galling, $n-$ a form of surface damage arising between sliding solids, distinguished by macroscopic, usually localized, rough- 
ening, and the creation of protrusions above the original surface; it is characterized by plastic flow and may involve material transfer.

Galling can therefore be understood to be an ad- 95 hesive wear mechanism and is most active at slow sliding speeds and relatively high compressive stresses. Gross plastic deformation of mated surfaces is particularly seen to occur when their movement is bound $50 \quad[9]$.

A number of works have investigated the mechanisms of galling and their relation to surface deformation. Some concluded that adhesion and galling occurs primarily through the agglomeration of wear particles and that these heavily work-hardened par $_{105}$ ticles adhere to one surface and gouge the opposing surface [10-13]. Other works have concluded that galling appears to occur through the adhesion of opposing asperities which shear to failure, and may also 60 result in the formation of peaks and troughs $[14,15]_{.110}$ Through this mechanism, layering of material has been observed to occur, resulting in the formation of the peaks and the formation of 'lips' in subsequently formed troughs [16-18].

65 Although work has predominantly been focussed upon the mechanism of surface deformation and failure, some work has also been carried out on the sub $b_{115}$ surface changes observed after adhesive wear and galling. A number of authors have reported the formation of 70 a heavily sheared sub-surface region [9, 19] which, for austenitic stainless steels has been found to contain strain-induced $\alpha^{\prime}$-martensite (SIM) $[19,20]$. $\mathrm{As}_{120}$ such, martensite is widely considered to be a source of galling resistance in stainless steels since the reduction in galling resistance correlates with the reduction in SIM formation at elevated temperatures [20]. This heavily sheared region is similar in appearance ${ }_{25}$ to the sub-surface microstructural changes observed after fretting, termed the white layer [21, 22].

Much of the work on galling in the literature has been concerned with the qualification of galling, with little work being produced on the quantification of ${ }_{130}$ galling. Examples of this include the ASTM G98 and G196 galling tests which state whether a sample has or has not galled at a given load, in order to find a threshold galling load, ASTM G98 [23], or the proportion of samples which gall at a given load (galling ${ }_{135}$ frequency), ASTM G196 [24]. Budinski and Budinski sought to improve the recording of results for these
90

tests by introducing a scoring system, corresponding to the type of damage seen e.g. burnishing, adhesive transfer and incipient galling, however, these results are not strictly speaking quantitative [25]. Ives et al. significantly developed the quantification of galling, using the average maximum peak-to-valley height, root-mean-square of $\mathrm{R}_{t}$, displaced volume and damage aspect ratio to quantify a single galled sample [26].

An area of research which has not been widely explored is the galling behaviour of an oxidised metal substrate, despite observations which suggest significant improvement of galling resistance in simulated light water reactor conditions, or when sample surfaces have a passive oxide layer [20, 27]. This knowledge gap is addressed in this work.

Many galling resistant stainless steels were developed from a base composition of 316 or 304 stainless steel, with the addition of large volume fractions of hard phases (carbides, nitrides or silicides). Here, $316 \mathrm{~L}$ stainless steel is used to investigate the galling behaviour of a stainless steel matrix material in both the bare-metal and oxidised states, without the complication of ceramic hard phase additions.

\section{Method}

316L bar, supplied by Goodfellow, was manufactured into ASTM G196 specimens with $\mathrm{R}_{t}=10 \mu \mathrm{m}$ (maximum height - maximum depth), and machined with the surface lay circumferential.

An autoclave was used to produce a representative pressurised water reactor (PWR) environment, enabling a representative oxide to be formed on galling specimens before testing. 316L stainless steels were oxidised at $300^{\circ} \mathrm{C}$ for $850 \mathrm{~h}$ in a static autoclave, with a water pressure of 120 bar. The water chemistry was controlled to contain $2 \mathrm{ppm} \mathrm{Li}$, which was added as LiOH,10.5 pH, $4 \mathrm{ppm}$ dissolved $H_{2}$ and less than 5 ppb of $\mathrm{O}_{2}$.

An ASTM G196 rig, Figure 1, was used to perform the galling tests. The primary reason for using the ASTM G196 rig was that the ASTM G196 test geometry has a uniform stress distribution and does not contain a dead zone (region of zero sliding distance), which is present in the centre of ASTM G98 tests [28]. As a result of the large number of samples required to perform a full ASTM G196 test and the availability of autoclave time to oxidise a sufficient number 
(a)

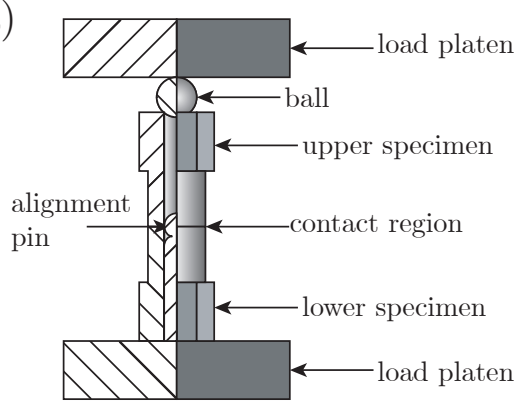

(b)

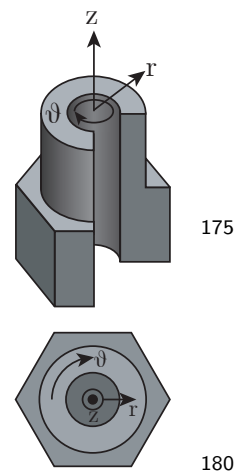

Figure 1: (a) ASTM G196 galling rig, redrawn from [24]; (b) ASTM G196 galling sample, with a section removed to an enable a view of the radial cross-section; (c) top view of an ASTM G196 galling sample.

of samples for this, only the ASTM G196 testing arrangement has been used in this experiment.

All tests were self-mated, in either the oxidised or non-oxidised state, and performed at ambient temperature and pressure. A torque of $350 \mathrm{~N} \mathrm{~m}$ was ap ${ }^{190}$ plied using a torque wrench, taking approximately $60 \mathrm{~s}$ to complete a single revolution. The torque wrench did not have a speed setting and could only perform partial revolutions, therefore requiring regripping during each test. For these reasons the test time is longer than that specified in the ASTM G196 standard. The normal stress was applied using a hy- ${ }^{195}$ draulic loading cylinder, controlled to $4 \mathrm{MPa}-103 \mathrm{MPa}$ (the lower limit of the equipment, and a representative contact stress for gate valves in nuclear power plant, respectively [29]). If a test pair seized, the test was finished when seizure occurred. If seizing oc 200 curred, the adhesive junction was broken before the mating surfaces could be observed.

Before testing, the mating surfaces were cleaned using propanol. After testing, surfaces were left undisturbed.

A white light interferometer and confocal microscope were used to detect surface topography and generate sample surface reconstructions.

Post-processing was employed to remove surface artefacts, sample edges and to generate data which ${ }^{10}$ was missing due to a lack of light detection. Linear interpolation of nearest neighbours was used to remove sample artefacts and reconstruct the full sample surface. In addition, surfaces were translated such that the minimally worn and ungalled regions were con-215 sidered flat and at the zero plane $(0 \mu \mathrm{m}$ in height $)$.

A number of galling measures developed and used by Ives et al. will be used in this work; the maximum height, depth and $\mathrm{R}_{t}$. In addition to these, the galled area was calculated, where the galled area is the proportion of the sample which is either above or below a threshold height value, corresponding to the initial surface $\mathrm{R}_{t}$.

Samples were prepared for metallographic examination by grinding through to 4000 grit $\mathrm{SiC}$ paper, using a diamond suspension as a first polishing stage, and a final polishing stage using an OPU suspension. Imaging was produced using SEM's in both secondary (SE) and backscattered electron (BSE) modes. EDX detectors in the SEM's were also used for imaging, as well as X-ray microanalysis.

In addition, a FIB/SEM was used to perform sitespecific in-situ lift outs for observation in a TEM. The TEM also contained STEM and STEM-EDX capabilities, which were used in conjunction with an x-ray diffraction (XRD) system in order to investigate oxide chemistries and structures and the fine sub-surface microstructural features seen as a result of galling.

Phase identification was performed using a TEM in diffraction mode and an XRD system.

\section{Results \& Discussion}

\subsection{Oxide Characterisation}

An in-situ lift-out was taken from an oxidised surface and shows that two oxide layers are formed on the surface of 316L after autoclaving in simulated PWR conditions for $850 \mathrm{~h}$, Figure 2. The outer oxide layer can be seen to be made up of discrete crystallites, whilst the inner oxide was nanocrystalline and free of pores and voids at the metal-oxide interface.

Compositional information, found using STEMEDX, showed that the outer oxide is Fe-rich and depleted of both $\mathrm{Cr}$ and $\mathrm{Ni}$. In contrast, the inner oxide is Cr-rich as well as containing both $\mathrm{Fe}$ and Ni, Figure 2 .

Structural information was found using XRD, showing that a single oxide structure was present, $\mathrm{M}_{3} \mathrm{O}_{4}$ (where $\mathrm{M}$ is a metal ion), often known as magnetite. The oxide peaks appeared as doublets, suggesting that both the inner and outer oxides have the same structure, but with differing lattice parameters, likely as a result of their different chemistries. The outer oxide was therefore found to be Fe-rich magnetite of composition $\mathrm{Fe}_{3} \mathrm{O}_{4}$, whilst the inner oxide is a Cr-rich magnetite of approximate composition $\mathrm{Cr}_{1.3} \mathrm{Fe}_{1.2} \mathrm{Ni}_{0.5} \mathrm{O}_{4}$, in agreement with Terachi et al. [30] and Kim [31]. 
(a)

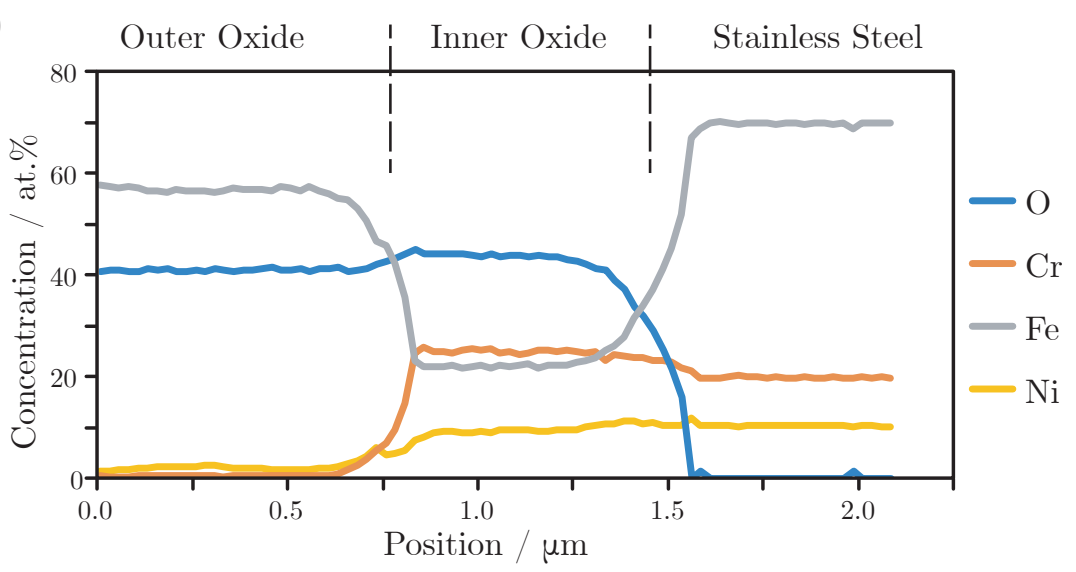

(b)

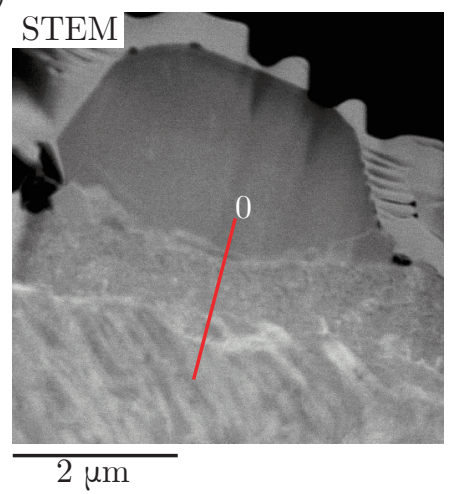

(c)

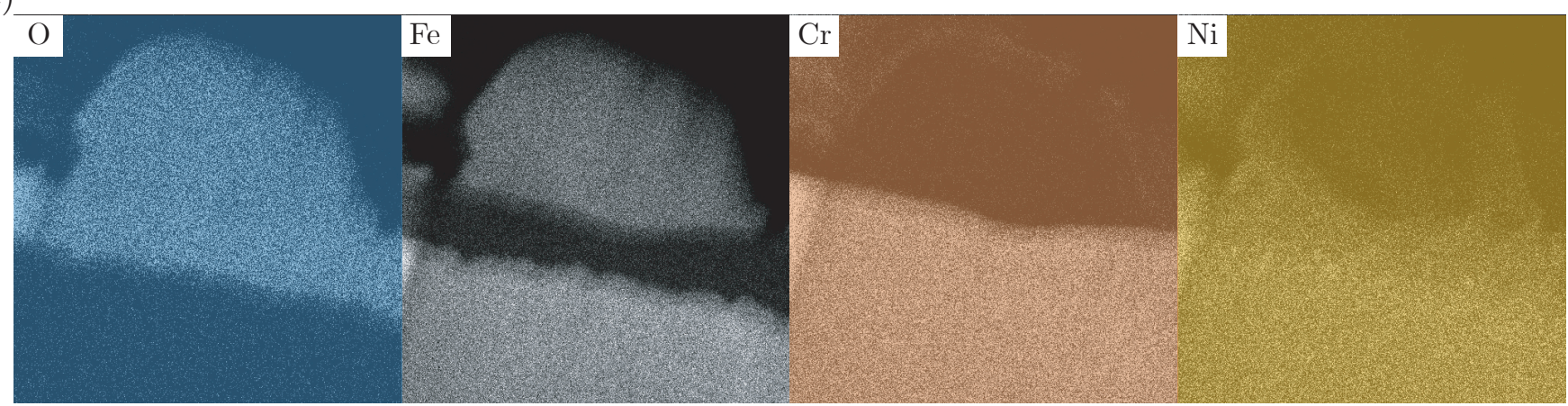

Figure 2: (a) The concentration profiles produced using STEM-EDX for the four primary elements in the oxides produced through autoclaving of 316L stainless steel. (b) A STEM image showing a cross-section of the oxides and the position of the STEM-EDX line scan. (c) EDX elemental maps for the region shown in (b).

\subsection{Macroscopic Observations}

In the non-oxidised condition, 316L stainless steel was seen to gall at the lowest applied stresses of 3.8 MPa. As a result, it was felt that the ASTM G98 standard"25 concept of a threshold galling stress was not a suitable measure of galling, since it is a purely qualitative moure and would nifferentiate between the extent of galling damage seen across different samples. In addition, since only three tests were performed at ${ }^{250}$ $5 \mathrm{MPa}$ and only one test at higher applied stresses, insufficient samples were tested for a complete ASTM G196 test and therefore galling frequency cannot be used as a measure of galling. As a result, quantitative measures developed by Ives et al. have been used in ${ }^{255}$ this work.

In the non-oxidised condition at an applied normal stress of $4.2 \mathrm{MPa}$ it was observed that $316 \mathrm{~L}$ formed a single galling peak and trough with a sample $\mathrm{R}_{t}$ of $780 \mu \mathrm{m}$ and a galling area of $14 \%$, Figure 3 . $\mathrm{It}^{260}$ was seen that when the applied normal stress was increased to $50 \mathrm{MPa}$ the galled area was seen to increase, as expected, however, the sample $\mathrm{R}_{t}$ decreased to $640 \mu \mathrm{m}$ when compared with the sample tested at $4.2 \mathrm{MPa}$. Since two samples are required for the galling tests, by observing the damage on the other sample within the test pair, it was seen that the average $\mathrm{R}_{t}$ for the test pair galled at $50 \mathrm{MPa}$ was in fact larger than that of the test pair galled at $4.2 \mathrm{MPa}$. There was, however, large variability in the $\mathrm{R}_{t}$ in non-oxidised samples tested across the applied normal stress range making a conclusion regarding the effect of applied normal stress on $\mathrm{R}_{t}$ difficult.

In contrast, the oxidised 316L stainless steel samples were seen to behave as expected, since both the $\mathrm{R}_{t}$ and galled area were seen to increase with increased applied normal stress across the full range of applied normal stresses, Figures $3 \& 4$.

For a given applied normal stress, the extent of galling seen by the non-oxidised samples was considerably greater than that of the oxidised samples, Figure 3. For the samples tested at a low applied stress, the $\mathrm{R}_{t}$ was also on a different order of magnitude when comparing 316L in the non-oxidised and oxidised conditions; $780 \mu \mathrm{m}$ vs. $26 \mu \mathrm{m}$. Although a less pronounced difference was observed with regard to $\mathrm{R}_{t}$, at high applied stresses, there was again a sig- 


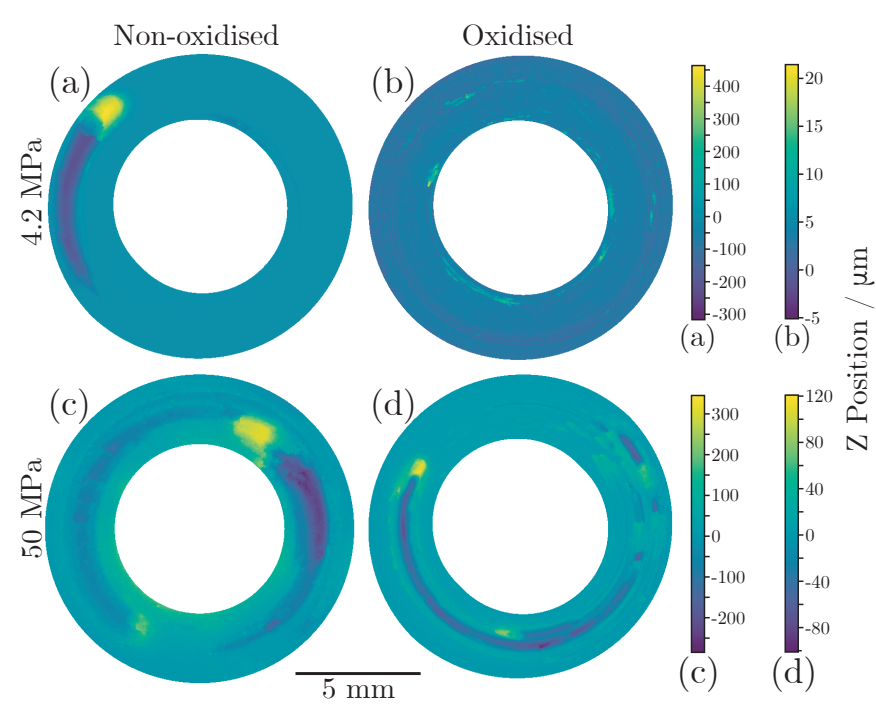

\begin{tabular}{ccccc}
\hline \hline \multirow{2}{*}{ Sample } & \multirow{2}{*}{ Galled } & \multicolumn{3}{c}{ Sample Height / $\mu \mathrm{m}$} \\
& Area / \% & Max & Min & Rt \\
\hline (a) & 14 & 460 & -320 & 780 \\
(b) & 1 & 21 & -5 & 26 \\
(c) & 59 & 350 & -280 & 630 \\
(d) & 28 & 120 & -100 & 220 \\
\hline
\end{tabular}

Figure 3: White light interferometry height maps of 316L samples in the non-oxidised (a) \& (c), and oxidised (b) \& (d) conditions, with their corresponding heights and height scales. nificant difference in the galled area, with the galled area being considerably larger when tested in the nonoxidised condition; $14 \%$ vs. $1.2 \%$, Figure 4 . This is unsurprising, since it is well known that adsorbed oxygen in ambient conditions gives rise to adhesion resistance when compared with adhesion under vacuum, and an oxide layer is a surface film which is more wear resistant than adsorbed oxygen [32, 33].

The most crucial finding was that for one of the non-oxidised tests at $50 \mathrm{MPa}$, seizure occurred before the end of the test, with the opposing surfaces needing to be pulled apart for observation, demonstrating the need to research how and why galling occurs. It is important to note that once the surface has been disturbed, the real contact area will be significantly reduced, resulting in a significantly increased contact stress. The applied stress of $50 \mathrm{MPa}$ is therefore only indicative of what can occur when the applied stress is increased.

It was also be noted that the number of galling prows on a surface appears to be larger on the oxidised samples than the non-oxidised samples, where typically there are only one or two galling peaks, Fig-

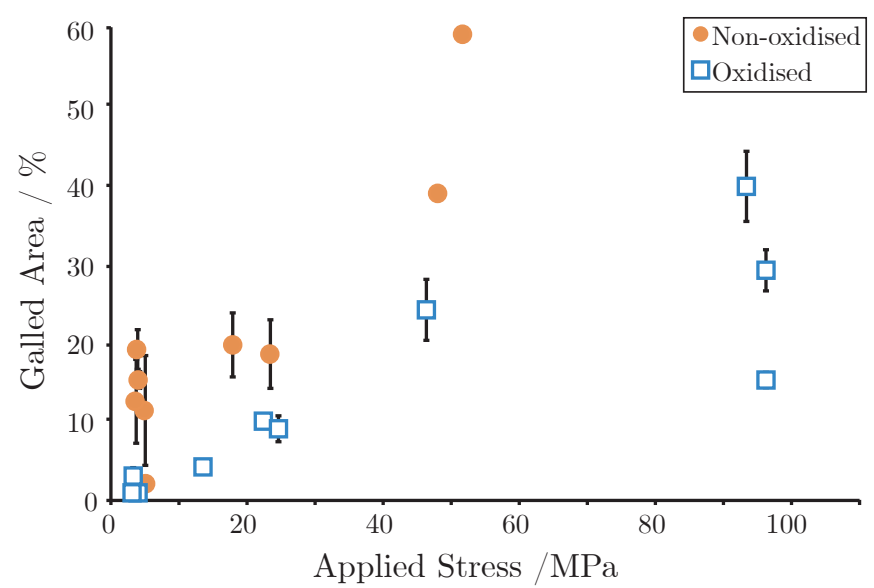

Figure 4: The effect of oxidation on galling for 316L stainless steel using galled area as a measure of galling severity. Error bars represent the difference between each surface of a single galled pair. Where these are small, the error bar is smaller than the marker.

ure 3. This suggests that either multiple galling instances take place simultaneously, or that prow growth is interrupted by oxide, and so abrasion recommences until metal-metal adhesion and subsequent galling can re-occur. The morphology of the galling scars was consistent throughout the tests, despite the change in damage magnitude. This behaviour suggests that the same mechanism was active for both the oxidised and non-oxidised samples.

\subsection{Galling Mechanisms}

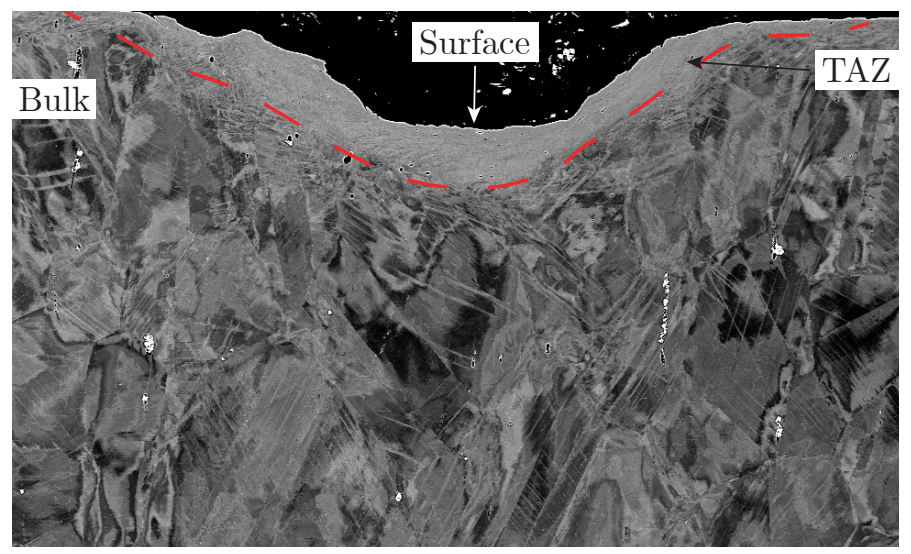

$100 \mu \mathrm{m}$

Figure 5: A radial cross-section of a galling trough in a nonoxidised 316L stainless steel sample tested at a normal load of 4.1 MPa.

By sectioning galled samples radially, the subsurface deformation can be easily seen, Figure 5. The 
most apparent change in microstructure from the as-350 received material is the creation of a layer of material immediately beneath the gall scar. This layer is often referred to as the 'white layer', 'tribologically transformed zone' or 'tribologically transformed structure' [9]. Since a transformation in phase or355 atomic structure may not necessarily occur, in this paper, this region is termed the 'tribologically affected zone' (TAZ), analogous with the heat affected zone (HAZ) in welding, and will be discussed at length later in this paper. When viewed in a radial cross-360 section using an SEM, the structure of the TAZ is difficult to interpret from BSE images. The size of the trough depth and the TAZ depth beneath, can however be observed and noted as being $67 \mu \mathrm{m}$ and $39 \mu \mathrm{m}$ respectively, Figure 5, demonstrating that ab65 significant damage layer is observed in galled samples.

When viewed in the circumferential plane the mechanism is easier to rationalise, Figure 6. Although more obvious in the non-oxidised sample, lips are seenz70 to have formed within the galling trough, Figure 6 . These lips are observed to be free of oxide. Similarly, in both the non-oxidised and oxidised states a large multilayered prow is seen. In the oxidised state, these prows are not made of discrete layers, sepa-375 rated by a partially worn oxide surface, instead, having regions of mechanical mixing between the oxide layers and stainless steel substrate. This was particularly seen in radial cross-sections, where fine-scale mechanical mixing within peaks was observed, Fig-380 ures $7 \& 8$. The prows are therefore unlikely to have formed through the accumulation of plucked material, instead, forming through shear. This is consistent with the formation of the lips, which are known to be formed through shear failure [34]. It is likely385 that as the prow grew it folded, and gave the appearance of a layered prow. This is particularly evident in the non-oxidised sample at the front of the prow, where the surface is observed to have buckled, Figure 6(a). This can also be evidenced in the oxidisedz9o sample through the adhesion boundaries which are seen to contain a relatively large proportion of oxide, which appear not to be in intimate contact, Figure $6(\mathrm{~b})$.

In order for the initial adhesion in the oxidised395 sample to take place, a metal-metal contact must first be achieved. This is due to oxide-oxide and oxidemetal adhesion bonds being very weak $[35,36]$. This therefore means that abrasion and removal of the ox- ide layers on both mating surfaces must occur before adhesion and galling may take place. The removal of the oxide layers therefore occurs through abrasion, with the abraded oxide being deposited in valleys within the surface, or within sample folds, Figure $6(\mathrm{~b})$.

Figure 8 shows a radial cross-section of a galling peak on an oxidised sample. The BSE image shows that within the bulk material there is extensive twinning, however, these were present in the as-received material. Twins were identified and distinguished from deformation-induced $\epsilon$-martensite by EBSD analysis. Immediately beneath the sample surface, oxide pile up as well as mechanical mixing of the surface, including oxides, can be seen, Figure 8. By performing EDX analysis it can be observed that both oxides have been both mechanically mixed and piled up, Figure 8. Between the region of mechanical mixing and the bulk, the TAZ is observed, however, it is difficult to interpret the microstructure of the TAZ using BSE in radial cross-sections. However, when observing the TAZ in a circumferential cross section, flow lines can be seen. In addition, although when viewed in radial cross-sections, carbide stringers appear unchanged from the as-received material, in circumferential cross-sections the carbide stringers are observed to follow flow lines, Figure 6(a). Since the carbide stringers are arranged perpendicular to the sample surface before-testing, by observing their posttest positions, it can be seen that extensive sub-surface shear has taken place, most notably by the shear lip, Figure 6(a).

A number of galling mechanisms have been reported in the literature, however, only one of these was observed in the galling of 316L stainless steel; wedge formation and flow, Figure 9 [12, 15]. The wedge formation and flow mechanism is consistent with the observations of galled 316L stainless steel in the non-oxidised condition by Peterson et al. [37].

Initially, adhesion of opposing surfaces takes place, either as two flat sections, in which case shear subsequently takes place to form a wedge $[12,15]$, or two asperities come into contact, essentially being premade wedges, Figure 9(a). Shear then continues to take place, causing material flow and wedge growth, Figure $9(\mathrm{~b})$. As the prow continues to grow and is pushed from behind, the leading face of the prow will eventually fold over [38], causing an additional interface within the prow, which, due to the compressive stresses it is under, will likely form an adhesion junc- 


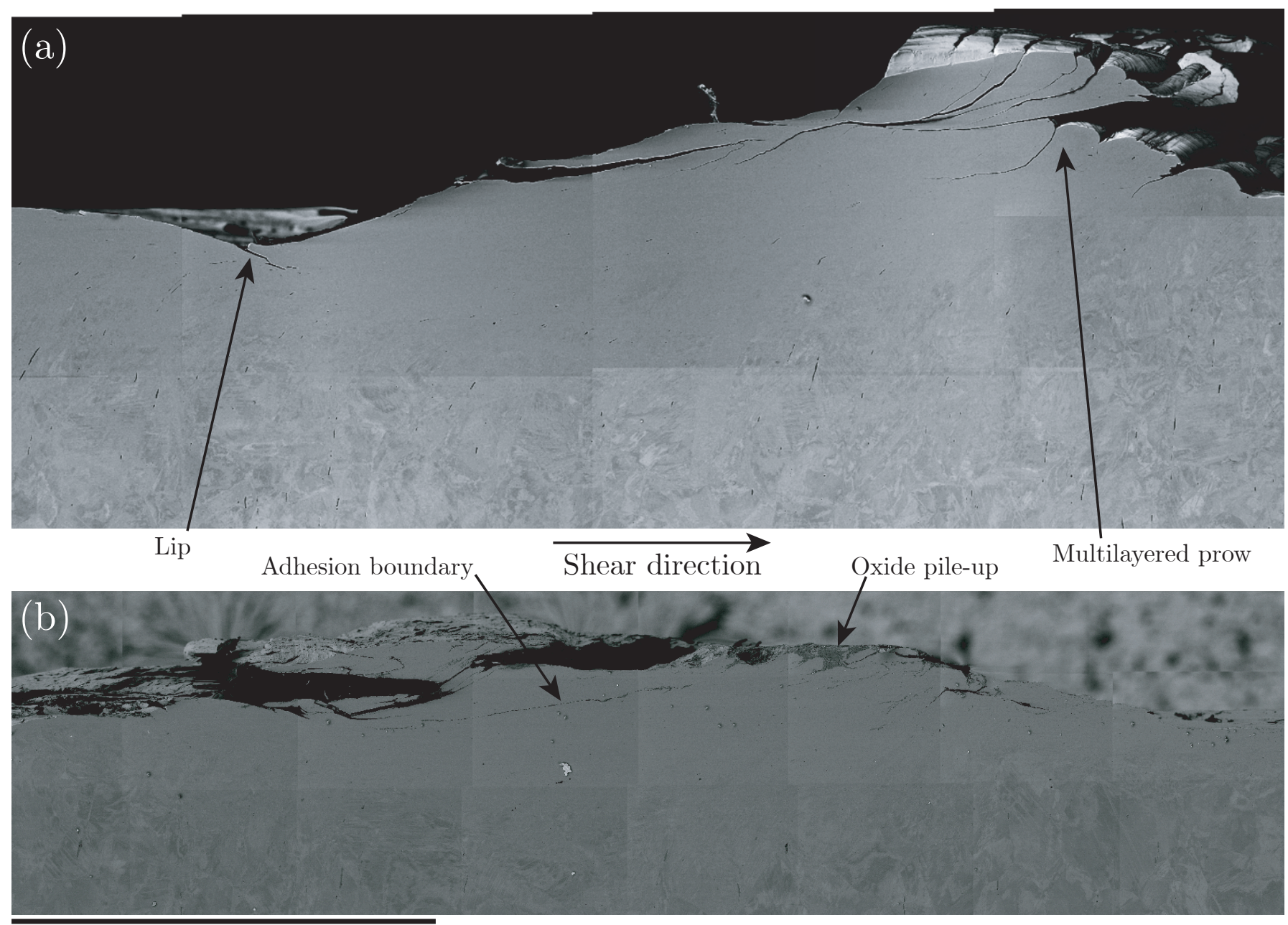

$0.5 \mathrm{~mm}$

Figure 6: Circumferential cross-sections through gall scars in 316L stainless steel. (a) A non-oxidised sample tested at 3.8 MPa, where lips formed through shear failure and multiple layers within the prow are clearly visible. (b) An oxidised sample tested at 93.6 MPa, where an adhesion boundary is visible due to the contrast of the oxide with the underlying stainless steel, and oxide pileup on the sample surface is seen. Both samples show a region immediately beneath the sample surface where the microstructure is no longer visible; the tribologically affected zone (TAZ). The scale of both images is common.

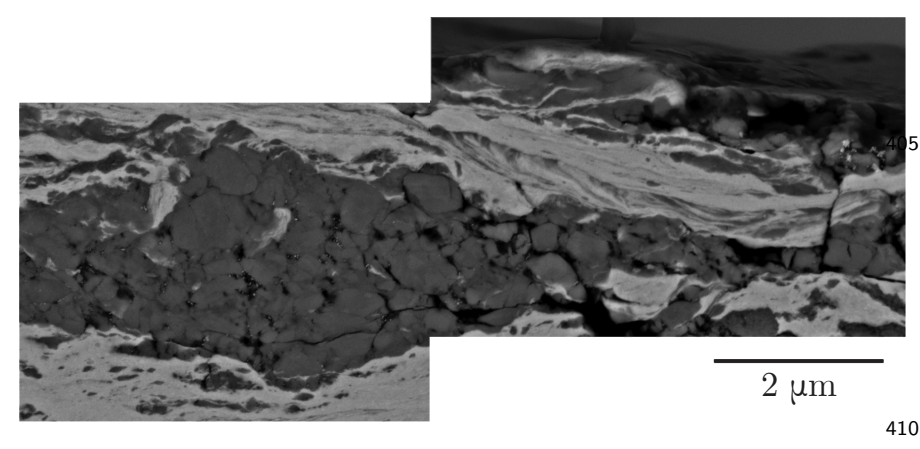

Figure 7: Fine scale mechanical mixing of the surface oxide layers (dark) with the underlying austenitic substrate (light).

tion. Simultaneously, the trailing face of the prow continues to move, shearing the sub-surface material, ${ }^{415}$ and resulting in the formation of 'lips' from shear fail- ure, within the galling trough, 9(d) [34]. This then continues such that multiple folds are formed as the wedge grows, whilst additional 'lips' are seen, Figure 9.

\subsection{Tribologically Affected Zone}

Something which has been studied very little in the literature is the sub-surface structure which results from galling. It is known that immediately beneath the galling scar, the hardness of the material is increased [20], particularly in the tribologically affected zone (TAZ).

TEM imaging was used to discern the microstructure of the TAZ by removing a section of the TAZ from a radial cross-section with a FIB. The TAZ was observed to be a nanocrystalline region where grains 

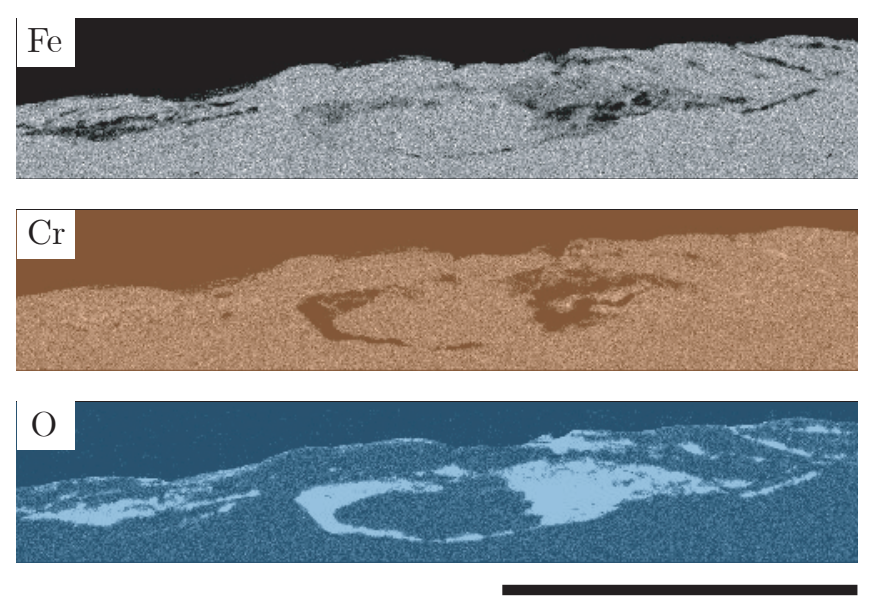

$100 \mu \mathrm{m}$

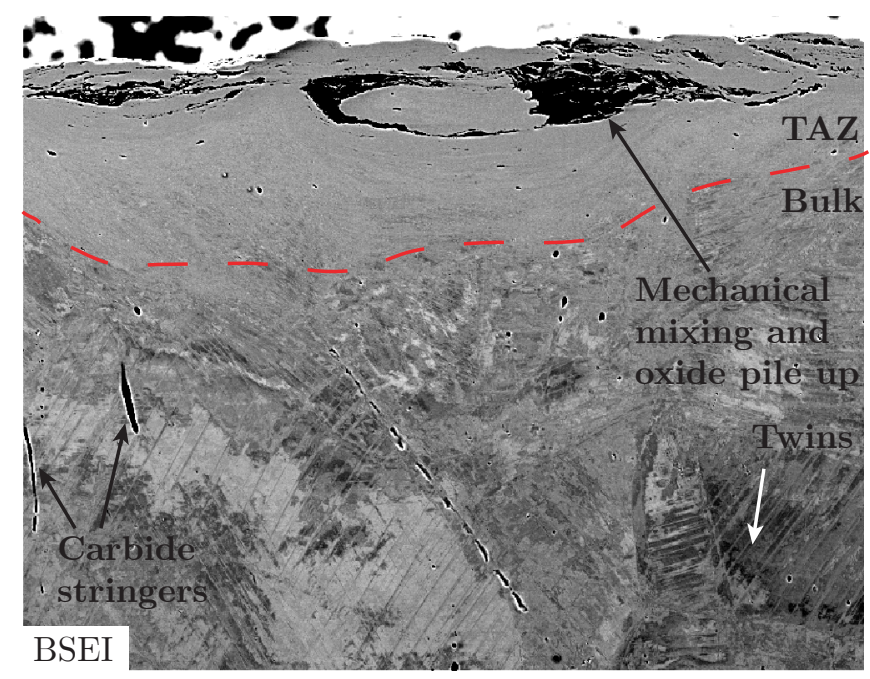

Figure 8: SEM-EDX imaging of a mechanically mixed region immediately beneath the sample surface. Both oxide layers are shown to be present by the chemical variation within the differing regions. The red box denotes the region examined using EDX.

are elongated in the shear direction, Figure 10. Since the sample was nanocrystalline, diffraction rings were formed, and the distance of these from the straight-450 through beam were measured and their crystal planes indexed. The indexing of these rings showed the presence of bcc-ferrite. This is surmised to be low-carbon (and hence low tetragonality) deformation-induced bct martensite formed without diffusion and compo-455 sitional change. This conclusion was verified using X-ray diffraction (XRD) and STEM-EDX.

Figure 11 shows the XRD patterns obtained for oxidised 316L both pre- and post-galling and additional peaks are seen, which are in positions corre- ${ }_{460}$ sponding to a bcc-phase. STEM-EDX found that the concentration of $\mathrm{Mn}$ (an austenite stabiliser), was constant across the sample, verifying the fact that a low-tetragonality bct-martensite phase has formed as a result of the extensive shear experienced immedi- ${ }_{465}$ ately below the galling surface.

In the literature, a number of authors consider such transformation induced plasticity (TRIP) behaviour to be beneficial in galling resistance, however, this is yet to be confirmed. [19, 32].

\section{Conclusion}

1. Self-mated oxidised and non-oxidised 316L stainless steel gall by wedge formation and flow.

2. In order for wedge formation and flow to be active in self-mated oxidised tests, sufficient oxide $_{475}$ must be removed to enable an adhesion bond stronger than a cohesion bond local to the ad- hesion surface. This therefore means that abrasion or mechanical mixing must first occur before gall can take place when $316 \mathrm{~L}$ is in the oxidised state, since oxide-oxide and metal-oxide adhesion bonds are significantly weaker than metal-metal adhesion bonds.

3. The magnitude of the damage seen by self-mated couples of oxidised $316 \mathrm{~L}$ is considerably less than that of the non-oxidised samples when galled at the same load $(780 \mu \mathrm{m}$ vs. $26 \mu \mathrm{m}$ under a normal load of $4.2 \mathrm{MPa})$.

4. A multilayered peak and a trough, with 'lips', indicative of shear fracture are formed during the galling of 316L and have been recorded as giving a sample $\mathrm{R}_{t}$ of up to $0.8 \mathrm{~mm}$.

5. In both the oxidised and non-oxidised states, an increase in normal load correspond to an increase in galling damage, as recorded using $\mathrm{R}_{t}$ and galling area.

6. A region of extensive shear is observed beneath galled surfaces, named the tribologically affected zone, TAZ. The TAZ has been found to be nanocrystalline, being a mixture of parent austenite and martensite, and formed during shear deformation.

\section{Acknowledgements}

We gratefully acknowledge support from RollsRoyce plc, from EPSRC (EP/N509486/1, EP/N025954/1 and EP/R000956/1) and from the Royal Society (D Dye Industry Fellowship). 


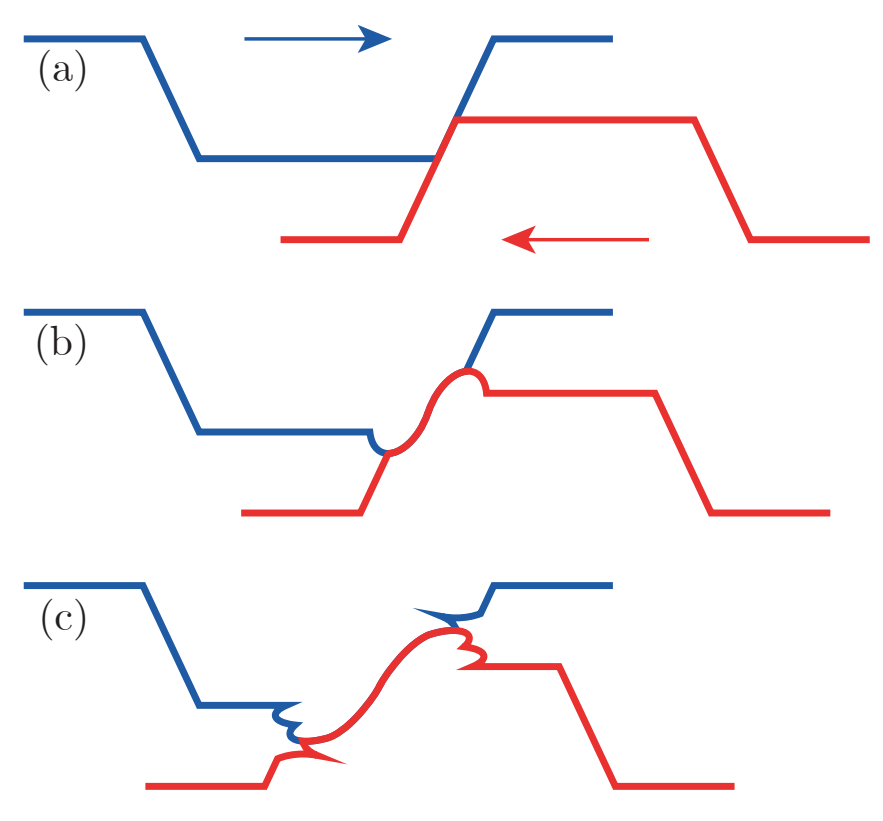

Figure 9: The wedge formation and growth galling mechanism seen in 316L stainless steel. (a) Two asperities come into contact and form an adhesive junction; (b) shearing of this junction results in wedge formation (this can also occur through the shearing of two flat surfaces that have adhered); (c) the wedge grows to such an extent that excess material ahead of the prows folds over, whilst shear failure occurs behind the prow, resulting in the formation of lips.

\section{References}

[1] M. Vannerem. Chemistry of operating civil nuclear reactors. ONR Guide NS-TAST-GD-088 Revision 2, Office for Nuclear Regulation, January 2019.

[2] H. Ocken. The galling wear resistance of new iron-base hardfacing alloys: a comparison with established cobaltand nickel-base alloys. Surface and Coatings Technology, 76-77:456-461, 1995.

[3] D.H.E. Persson, S. Jacobson and S. Hogmark. Effect of temperature on friction and galling of laser processed norem 02 and stellite 21. Wear, 255(1):498-503, 2003.

[4] D. Bowden. Assessment of cobalt-free hardfacing stainles ${ }_{510}$ steel alloys for nuclear applications. $\mathrm{PhD}$ thesis, University of Manchester, 2016.

[5] J.H. Magee. Two galling resistant stainless steels used for bridge hinge pins. Technical report, Carpenter Technology Corporation, 2018.

[6] Committee of Stainless Steel Producers. Review of the wear and galling characteristics of stainless steels. Handbook.

[7] I. Inglis, E.V. Murphy and H. Ocken. Performance of wearresistant iron base hardfacing alloys in valves operating ${ }_{520}$ under prototypical pressurized water reactor conditions. Surface and Coatings Technology, 53:101-106, 1992.

[8] ASTM International. ASTM G40-15, Standard Terminology Relating to Wear and Erosion. West Conshohocken, PA; ASTM International, 2015. DOI ${ }_{525}$ https://doi.org/10.1520/G0040-15

[9] I. Hutchings and P. Shipway. Tribology: Friction and Wear
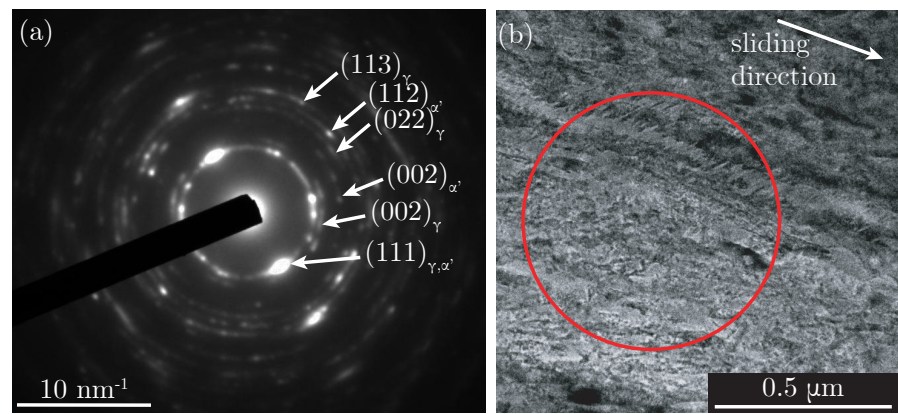

Figure 10: (a) A TEM diffraction pattern of the region shown in (b), which is a portion of the tribologically affected zone immediately beneath a galling trough. An in-situ FIB lift-out was taken from a non-oxidised sample which had been galled at $4.1 \mathrm{MPa}$ and radially cut.

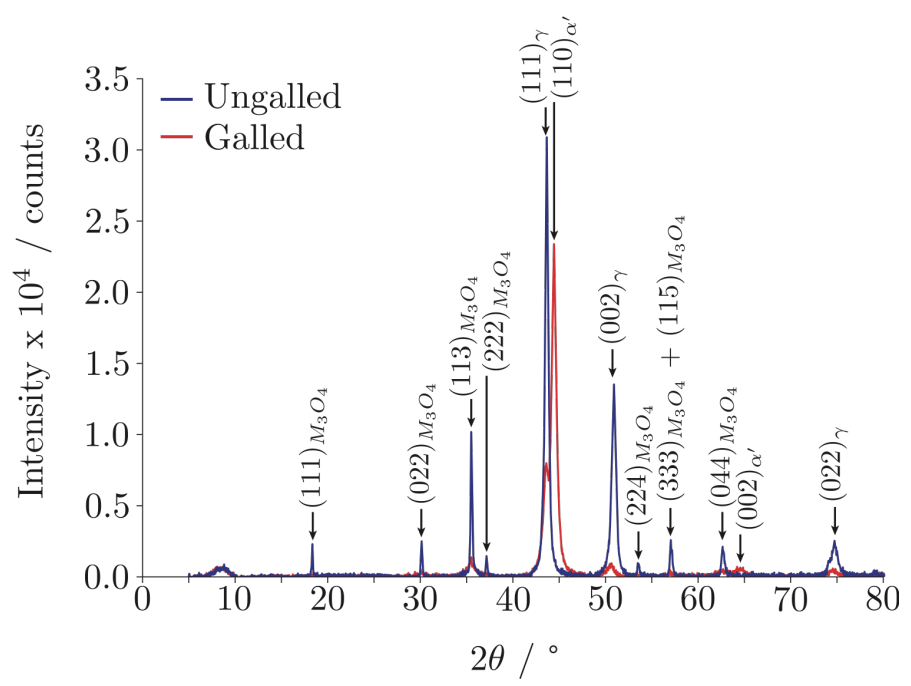

Figure 11: X-ray diffraction patterns of samples which had been oxidised in simulated autoclave conditions and where one sample was then galled at $96.5 \mathrm{MPa}$.

of Engineering Materials. Butterworth-Heinemann, second edition edition, 2017.

[10] M. Cocks. Wear debris in the contact between sliding metals. Journal of Applied Physics, 29:1609-1610, 1958.

[11] M. Antler. Wear, friction, and electrical noise phenomena in sever sliding systems. ASLE Transactions, 5:297-307, 1962 .

[12] M. Antler. Processes of metal transfer and wear. Wear, 7(2):181-203, 1964.

[13] T. Sasada and S. Norose. The formation and growth of wear particles through mutual material transfer. In Proceedings of the JSLE-ASLE International Lubrication Conference, p 82-91, 1976.

[14] M. Cocks. Interaction of sliding metal surfaces. Journal of Applied Physics, 33(7):2152-2161, 1962.

[15] M. Cocks. Role of displaced metal in the sliding of flat metal surfaces. Journal of Applied Physics, 35(6):18071814, June 1964.

[16] W.A. Glaeser. Wear experiments in the scanning electron microscope. Wear, 73(2):371-386, 1981. 
[17] T. Kayaba, K. Kato and Y. Nagasawa. Abrasive wear in stick-slip motion. In Wear of Materials: Internationab90 Conference on Wear of Materials, 1981, p 439-446, 1981.

[18] T. Kayaba and K. Kato. The analysis of adhesive wear mechanism by successive observation of the wear process in sem. In Wear of Materials, p 45-56, April 1979.

[19] R.T. Smith. Development of a Nitrogen-Modified 695 Stainless-Steel Hardfacing Alloy. PhD thesis, The Ohio State University, 2015.

[20] J.-K. Kim and S.-J. Kim. The temperature dependence of the wear resistance of iron-base NOREM 02 hardfacing alloy. Wear, 237(2):217-222, February 2000.

[21] E. Sauger, L. Ponsonnet, J.M. Martin and L. Vincent. Study of the tribologically transformed structure created during fretting tests. Tribology International, 33(11):743$750,2000$.

[22] V. Nurmi, J. Hintikka, J. Juoksukangas, M. Honkanen, M. Vippola, A. Lehtovaara, A. Mantyla, J. Vaara and T. Frondelius. The formation and characterization of fretting-induced degradation layers using quenched and tempered steel. Tribology International, 131:258-267, March 2019.

[23] ASTM International. ASTM G98-17, Standard Test Method for Galling Resistance of Materials. West Conshohocken, PA; ASTM International, 2017. DOI: https://doi.org/10.1520/G0098-17.

[24] ASTM International. ASTM G196-08(2016) Standard Test Method for Galling Resistance of Material Couples. West Conshohocken, PA; ASTM International, 2016. DOI: 2016.

[25] K.G. Budinski and S.T. Budinski. Interpretation of galling tests. Wear, 332(C):1185-1192, 2015.

[26] L.K. Ives, M.B. Peterson and E.P. Whitenton. The mechanism, measurement, and influence of properties on the galling of metals. Technical Report NISTIR 89-4064, National Institute of Standards and Technology (NIST), December 1989 .

[27] S.R. Hummel, B. Partlow. Comparison of threshold galling results from two testing methods. Tribology International, 37(4):291-295, April 2004.

[28] S.R. Hummel. Development of a galling resistance test method with a uniform stress distribution. Tribology International, 41(3):175-180, March 2008.

[29] H. Ocken. Reducing the cobalt inventory in light water reactors. Nuclear Technology, 68:18-28, January 1985.

[30] T. Terachi, T. Yamada, T. Miyamoto, K. Arioka and K. Fukuya. Corrosion behavior of stainless steels in simulated pwr primary water - effect of chromium content in alloys and dissolved hydrogen. Journal of Nuclear Science and Technology, 45(10):975-984, 2008.

[31] Y.-J. Kim. Characterization of the oxide film formed on type 316 stainless steel in $288^{\circ} \mathrm{C}$ water in cyclic normal and hydrogen water chemistries. Corrosion, 51(11):849860, 1995.

[32] D.H. Buckley and R.L. Johnson. Friction and wear of hexagonal metals and alloys as related to crystal structure and lattice parameters in vacuum. ASLE Transactions, 9(2):121-135, 1966.

[33] D.H. Buckley. Surface films and metallurgy related to lubrication and wear. Progress in Surface Science, 12(1):1154,1982

[34] O. Vingsbo. Wear and wear mechanisms. In Wear of
Materials, p 620-635. ASME, 1979.

[35] O.L. Anderson. Adhesion of solids: Principles and applications. Bell Laboratories Record, 35(11):441-445, 1957.

[36] S.B. Ainbinder and A.S. Frančs. On the mechanism of the formation and destruction of adhesion junctions between bodies in frictional contact. Wear, 9(3):209-227, 1966.

[37] M. Peterson, K.J. Bhansali, E.P. Whitenton and L.K. Ives. Galling wear of materials. In American Society of Mechanical Engineers Wear of Materials: International Conference: Papers, p 293-301, 1985.

[38] H. Yeung, K. Viswanathan, A. Mahato and S. Chandrasekar. Surface phenomena revealed by in situ imaging: studies from adhesion, wear and cutting. Surface Topography: Metrology and Properties, 5(1):014002, 2017. 